\title{
Successful vs. Less Successful Iranian EFL Learners: Cognitive Styles, Cognitive Flexibility, and Experience Evaluation
}

\author{
Farnaz Avarzamani ${ }^{1} \&$ Majid Farahian ${ }^{1}$ \\ ${ }^{1}$ Department of ELT, College of Literature and Humanities, Kermanshah Branch, Islamic Azad University, \\ Kermanshah, Iran \\ Correspondence: Majid Farahian, Department of ELT, College of Literature and Humanities, Kermanshah \\ Branch, Islamic Azad University, Kermanshah, Iran. E-mail: farahian@iauksh.ac.ir or \\ farnaz.avarzamani@gmail.com
}

Received: January 2, 2017 Accepted: January 22, 2017 Online Published: February 9, 2017

doi:10.5539/ijel.v7n3p29 URL: http://dx.doi.org/10.5539/ijel.v7n3p29

\begin{abstract}
The present study aimed to compare successful with less successful English as a Foreign Language (EFL) learners regarding their cognitive styles and flexibility, together with the learners' evaluation of their experience of doing an unfamiliar cognitive test. The sample consists of 60 adult EFL learners (30 successful and 30 less successful), both males and females symmetrically. The homogeneity of participants' age of onset, socio-economic class, and motivation was also considered. The data was analyzed, using Chi-square and Gamma correlation. Overall, it was revealed that analytical, logical reasoning, reflective, and learning were the most prominent cognitive styles among successful learners. They also showed a considerable cognitive flexibility. On the other hand, less successful learners were inclined to the random style, along with a lower cognitive flexibility. With respect to gender groups, it turned out that females in the successful group were significantly inclined to the reflective and logical reasoning styles and less successful females adopted a random style. Finally, no significant result was found concerning the cognitive test evaluation. The findings of this study may contribute to a wider understanding of EFL success and failure from the viewpoint of cognitive preferences.
\end{abstract}

Keywords: cognitive flexibility, cognitive style, experience evaluation, successful language learners

\section{Introduction}

The role of cognitive styles, which are partially stable individual differences in preferred ways of information processing (Evans, Cools, \& Zarina, 2010), has been investigated by scholars in numerous fields of study, mostly related to psychology, education, and business as large contexts (Zhang, Sternberg, \& Rayner, 2012). The particular importance of cognitive styles was perceived in the EFL fields since the 1960s (Salmani-Nodoushan, 2007). From the outset, many of the measurement tools, mostly dichotomous ones, were borrowed from the cognitive psychology. Along with the development and research in this domain, the carried out studies confronted many troubles and criticisms, especially in terms of measurement tools. For example, many scholars leveled fundamental criticisms at cognitive and learning style measures regarding their validity and reliability and also their limited scope (Davies, 2009; Ehrman, 1994; Frisby, Mansson, \& Kaufmann, 2014; Marx \& Otto, (as cited in Tiedemann, 1989); Michonska-Stadnik, 2013; Norton \& Toohey, 2001; O'Leary, Calsyn, \& Fauria, 1980; Prinsloo, 2013; Tiedemann, 1989; Williams, 1975; Zelinker, Bentier, \& Renan, 1977). In addition, some have highlighted severe problems of questionnaires in that they generally put a limit on participants when answering questions (Murray, 2010).

Specifically concerning the procedures of cognitive/learning tests, Price (2004), argued that the tasks involved in the commonly used style measurement tests like Learning Style Questionnaire (LSQ), Group Embedded Figures Teat (GEFT), and Cognitive Style Analysis (CSA) are not learning activities and thus could not clearly reflect learners' performance in real learning situations. Moreover, Goel (2010), contended that the tasks in the available cognitive tests are well-structured and well-defined, which do not resemble the real world problems. On the other hand, there are some learning-oriented tests like Learning Loss measure (LL) that are based on the respondents' self-reports (Frisby et al., 2014). Nevertheless, they were questioned regarding both the filtering effects of self-reporting and the variations in "students' ability to report their own learning" (Frisby et al., 2014, p. 164). 
As a partial response to the lack of a valid and comprehensive measurement tool to pore over cognitive styles, specifically in the domain of EFL studies, some scholars attempted to create new measures. As an instance, Ehrman \& Leaver (2003), created a multidimensional measure, called E\&L Learning Styles Questionnaire, which is composed of ten subscales to refer not only to dichotomous cognitive styles but also learning and information grouping preferences which have infrequently been researched. Besides, Bakhoda \& Shabani (2016), used a process-based procedure to record the EFL learners' ongoing responses in the process of reading comprehension. Despite such attempts to devise a comprehensive measure, no conclusive and consistent results were reached. To fill the gap in the field of cognitive measurement tools in general, the CPP (Cognitive Process Profile), was created by Prinsloo (1992), which is still improving, as a compensation for critical shortages of old measures.

The CPP is a multidimensional computerized simulation of human problem-solving processes in terms of cognitive preferences and tendencies in which the respondents' cognitive traits are assessed deeply through a game-like software, including the tasks that are quite ambiguous for the testees. This ambiguity was deliberately generated in the test as an attempt to mimic the novelty which is embedded in the real world. According to Barrett (2015), "A person's stylistic preferences when dealing with unfamiliar information, however, also tend to be used when working with familiar information" (p. 5). Interestingly, The CPP tasks are relatively immune from functional fixedness (Note 1) and mental set (Note 2), due to its unfamiliarity and flexibility. Plus, the tasks are fairly ill-structured and ill-defined within which there is no right or wrong answer. In addition, respondents are not under time pressure to complete the CPP and thus they can do the test at their own pace. As Prinsloo remarked (September, 2016), "our assessment methodologies were primarily created to improve on the shortcomings of existing measurement techniques such as IQ tests, personality questionnaires, and interviews" (p. 2).

As already stated, there is a strong need to use some innovative and valid cognitive measures in EFL studies. Even though there have been attempts in this domain to develop adequate measures, a majority of researchers are in need of more well-grounded tools to measure cognitive traits, and there is a worry for EFL/ESL (English as a Second Language) scholars to lag behind the progress made in cognitive psychology and psychometrics. Therefore, we decided to employ the CPP as an advanced and innovative psychometric tool so as to yield some new insights, especially regarding EFL learners' success in standardized tests like IELTS (International English Language Testing System).

Having such a purpose in mind, we looked into the cognitive style and cognitive flexibility of good language learners and their differences with less effective learners. According to Rubin and Stern, good language learners "are more willing to make linguistic guesses, are more able to tolerate confusion, uncertainty and shifting structures; and they can revise their expectancies without undue stress. All of this is indicative of a high degree of cognitive flexibility" (as cited in Ramsay, 1980, pp. 73-74). They are also capable of dealing with analytic tasks which require rule extraction (Skehan, 1998). In this study we also looked for possible relationship between participants' EFL achievement and their self-evaluation on the cognitive test. It should be noted that although many scholars (Arnup, Murrihy, \& Roodenburg, 2013; Oxford, Nyikos, \& Ehrman, 1988) have highlighted the importance of gender as a factor, the results are severely inconsistent. Furthermore, findings of those studies in the realm of EFL which have investigated the role of gender with respect to cognitive styles have yielded less consistent results (e.g., Saricaoglu \& Arikan, 2009). This led us to consider the gender factor in all the analyses we conducted in this study. It is also noteworthy that we built our study upon previous cognitive styles studies in the EFL domain, though the primary purpose was to find the styles that have not already been investigated. We believe that finding and studying further cognitive styles will expand and deepen our knowledge about the issues involved in both FL (Foreign Language) learning, where the target language is not widely used in the learners' society, and also about learning a language in SL (Second Language) contexts, where the target language is used in the learners' community on a daily base. In the following paragraphs, the related studies are reviewed briefly.

\section{Literature Review}

\subsection{Cognitive Style Dichotomies}

There are various classifications for cognitive styles with their subcategories in the literature (e.g., Riding \& Rayner, 1998), but the most well-known two-dimensional styles in the EFL studies that are directly related to this study are: reflective/impulsive, and global/analytic.

The Kagan's (1966) reflective/impulsive is a well-known dichotomy. According to Riding \& Rayner (1998), these styles are distinguished by the tendency to provide quick (impulsive) or deliberate and slower (reflective) 
responses. As regards good language learners, a considerable amount of research findings support the positive impact of reflective style in language achievement. As an instance, Halpern (1984), noticed a substantial literature confirming higher reading proficiency in reflective learners. Intriguingly, some researchers found participants who were neither impulsive nor reflective and thus some scholars argued that more branches remained to be identified regarding these styles (Eska \& Black, 1971; Keller \& Ripoll, 2001; Michonska-Stadnik, 2013).

Another well-known dichotomy of cognitive styles is known as global/ analytic (Miller, 1987). Analytic learners are more inclined to focus on rules, analysis, and language comparisons and they usually avoid the activities which entail free communication. On the contrary, global learners prefer conversational activities rather than language analysis (Ehrman \& Oxford, 1995; Oxford et al., 1991). Further, Littlemore (2001) revealed that the participants who had a holistic cognitive style outperformed analytic ones in terms of finding particular meaning in metaphors. On the other hand, Skehan (1998) emphasized the important role of analytic skills in language learning achievements. As can be implied, the research results regarding the global/analytic dichotomy are less consistent (Zhang, Sternberg, \& Rayner, 2012).

\subsection{Cognitive Flexibility}

Style flexibility/inflexibility was termed "mobility/fixity" by Kozhevnikov (2007), which "defines the level of flexibility with which an individual chooses a particular style in a particular situation" (p. 472). This is in line with the CPP's definition of cognitive flexibility which is the ability to use varied approaches while solving novel problems. This characteristic is widely believed to be a facilitator for students' higher achievements. For example, Niaz (1987), proposed that students with considerable malleability performed better in different fields. Successful FL learners, in particular, were also marked by their flexible cognitive preferences. In this regard, Biedroń \& Szczepaniak (2009), studied a good FL student from different facets of intelligence, including cognitive style, and finally found that the learner was notably flexible, with a high analytical ability at the same time. Accordingly, Ehrman \& Oxford (1995), maintained that the flexibility of learners is quite beneficial since they can move out of their comfort zone. As was compared by Chapelle \& Roberts (1986), successful learners were capable of adapting a given task to a situation, contrary to their less successful counterparts who were persistent with their style. In a recent study, Kozhevnikov, Evans, \& Kosslyn (2014), strongly emphasized the importance of having cognitive flexibility in different situations and task demands. As we discerned, the majority of research results acknowledge the positive impact of having relatively higher cognitive flexibility on learning a new language.

\subsection{The Role of Gender}

In the field of education, females were usually recognized to be superior in language capabilities. As Oxford, Nyikos, \& Ehrman (1988) argued, women have an early advantage over men regarding their language use and practice of formal rules. Nonetheless, it is not true for all cultures (Kaylani, 1996). On the other hand, Arnup, Murrihy, \& Roodenburg (2013), suggested that cognitive styles affect boys and girls differently. With respect to learning style and reasoning, Severiens, Dam, \& Nijenhuis (1998), found no significant difference between the two genders. According to a review, males and females were not dissimilar in their language learning strategies and the only distinction was that women used more strategies than men (Oxford, Nyikos, \& Ehrman, 1988). Saricaoglu \& Arikan (2009) also did not find any notable gender difference in terms of intelligence types in foreign language success. Concerning online EFL learning contexts, no noticeable difference was found between two genders in using the strategies they preferred (Marimuthu, Chone, Heng, Nah, \& Fen, 2013).

The research history of male/female cognitive differences have been troubled many times (Davis, 1992). For example, the males' superiority in spatial abilities has been shown to be the result of some measurement tools which were in favor of males. Although many scholars like Halpern (1984), called for more attention to cognitive processes, rather than crystallized cognitive traits, in comparative gender studies, this issue is still ignored in many EFL studies.

\subsection{The Importance of Learners' Evaluation}

We assumed that the participants' ideas about cognitive tests and their performance on them, generally termed as experience evaluation, might have something to do with higher/lower EFL achievements, and this might also be varied between males and females. As highlighted by White (2008), learners' beliefs affect the way they interpret their experiences and behaviors. Additionally, Shouksmith (1972), reported that cognitive styles could guide students' self-evaluation. However, according to Benson \& Lor (1999), learners' beliefs are malleable since they can vary under different circumstances and task demands and this was termed as the "self-efficacy perception" by Brophy (2004), who remarked that "Self-efficacy perceptions can influence task choice and the quality of task engagement" (p. 64). 


\subsection{Research Questions}

The following research questions were formulated based on the objectives of the study.

1) Is there any significant difference(s) between successful and less successful EFL learners regarding their cognitive styles?

2) Is there any significant difference(s) between successful and less successful EFL learners regarding their cognitive flexibility?

3) Is there any significant difference(s) between males and females EFL learners regarding their cognitive styles?

4) Is there any significant difference(s) between males and females EFL learners regarding their cognitive flexibility?

5) Is there any relationship between EFL Learners' experience evaluation and their EFL achievement?

6) Is there any relationship between EFL Learners' experience evaluation and their gender?

\section{Method}

\subsection{Participants}

Overall, 60 EFL learners were recruited for the present study who were selected from an IELTS training center in Tehran. They were all adult EFL learners who were in the age range of 22 to 35 and, as they remarked, had started learning English after puberty. The IELTS learners (academic module) shared a common motivation for learning English since they were looking for continuing their studies abroad. They were also motivated to do the CPP since they were convinced by the CPP administrator that it would help them to know their cognitive and intellectual characteristics better. Additionally, the participants belonged to the middle to upper-middle socio-economic class with various university majors (based on their reports in an initial informal interview, without letting them know the research purpose).

They were randomly selected from 3 classes belonging to an intensive IELTS course. The information regarding the learners' major strengths and weaknesses in English language learning was obtained from the participants and their teacher. For example, successful learners gained their desired band scores (8) in a 6-month English course at the institute, while many others admitted that their band scores remained persistently between 5 to 6 , though they studied hard and took the test several times (For the IELTS band scores descriptions, see Appendix D). Surprisingly, the majority of the less successful learners acknowledged that they have already had this slow progression problem since they got into the intermediate level in recent years. These remarks resemble what Wei (2008), called a "temporary fossilization" and are in tandem with Xu (2009), who termed this as "plateau period". As a clarification, this type of stagnation often takes place in the intermediate stage of language learning in which moving toward upper-intermediate and advanced levels becomes notoriously slow and difficult. In fact, it happens when language learners do not make a considerable or perceptible progress anymore, even when they study a lot. In fact, we aimed to find the extent to which the EFL success and failure of our participants could be explained by the major cognitive differences.

\subsection{Instrumentation}

\subsubsection{The Theoretical Background of the CPP}

The theoretical background of the CPP emanates from cognitive psychology and intelligence theories which is based on an integrated theoretical model that combined the structural with process approaches. The former speculates that the human mind, memory as an example, comprises separate components such as short-term and long-term memory, whereas the latter focuses mainly on the processes involved in mental activities (McLeod, 2007). In this regard, Royce \& Powell (1981) maintained that the structures and dynamics are complementary components in one's psychological system.

The CPP is unprecedented in the history of FL/SL research. However, the test had been used in the fields of psychometrics, human resources management, and academic performance. As an instance, Farquharson (as cited in Prinsloo, 2013), applied the CPP in a study to predict educational performance and finally came to the result that the ability to deal with complexity was the most significant predictor among others in educational attainments.

Above all, the CPP's validity and reliability were extensively examined by its developer and researchers. According to its research manual (2013), the CPP's construct validity was evaluated by the CFA (Confirmatory Factor Analysis) method, and the results showed that the validity of most of the cognitive processing constructs was acceptable. In addition, other types of validity (e.g., concurrent, predictive, criterion, etc.) of this test were 
also examined which were reported in depth in the manual (2013). As to the reliability of the CPP, it should be stated that since it assesses respondents' thinking styles by engaging them in solving unfamiliar problems, it is illogical to administer a CPP re-test in a short time span.

Owing to the critical importance of preserving the test novelty for the public, we provided a blurred image of one of the CPP's levels (Appendix A). As Barrett (2015) stated, “Because the CPP capitalizes on a person's cognitive response to new and unfamiliar information, the first CPP is always the most valid-particularly if the individual's performance has not been affected by extreme performance anxiety or demotivation" (p. 10). Elsewhere in the report, it was claimed that the CPP components show an excellent re-test reliability, with the Gower similarity coefficient of $81 \%$, obtained after two months, and this is compatible with or even better than conventional psychometric tests (Barrett, 2015).

\subsection{Procedures}

As one of the main rules of the CPP administration, the test sessions were held in the morning times. Before starting the test, the participants were given an overview of the test so as to help them get ready. Then they filled in a form electronically in the CPP software with their demographic data (i.e., age, sex, education, employments, etc.).

The CPP starts with a practice level before the main assessment which is for participants to learn the general rules of the test. During the test, the participants were allowed to take a-few-minute rest between the levels. In fact, participants were supposed to construe some figures symbolically, using some clue cards (Appendix A). Next, they typed down their stories about the symbols briefly in English. After completing the CPP, there was a short evaluation questionnaire in the CPP software with a 4-point Likert-type response format (Appendix C). Depending on the respondents' pace, the CPP took one or two hours to complete. The test administrator held a brief interview with the participants after the test session about their experience in order to make sure that the participants did not select the provided responses in the evaluation questionnaire randomly.

After each assessment, the software generated a file with a unique format. Then the administrator sent the files separately to the test provider company to ask them to convert the files to the final CPP reports (PDF format). Regarding the system used for generating the CPP reports, Prinsloo \& Barrett (2013) stated, "A scoring and statement parsing system subsequently integrates all these movements and "story" interpretations, which are subsequently analysed using more algorithms to produce the CPP report" (p. 28). Here the term "story" refers to the participants' interpretations written about the central symbols in the test (Appendix A).In fact, the final report for each person was an in-depth report of their cognitive profile, including many scores and descriptions and the data we analyzed in this study was only a portion of the participants' cognitive reports (Cognadev, 2015).

\subsection{Research Design}

This study adopted a quantitative approach which was non-experimental since there was no treatment or manipulation of the variables.

\subsection{Data Analysis}

To find the differences among the EFL learners, we employed the Chi-square Test for Independence, and for the sake of post-hoc testing for gender groups, we calculated the Chi-square residuals. For the analysis of the data related to the second section, namely experience evaluation, we conducted Gamma Correlation. We used the SPSS (Statistical Package for the Social Sciences), version 22, for all the analyses.

\section{Results}

Totally, 60 learners' cognitive reports were analyzed in this study. Note that both proficiency and gender groups were equal regarding their size (symmetrical). Table 1 shows the descriptive statistics related to the identified cognitive styles, plus flexibility among successful and less successful EFL learners. It should be noted that the definitions of the CPP's cognitive styles are available in Appendix B. 
Table 1. Descriptive statistics

\begin{tabular}{lllll}
\hline Cognitive styles & & Successful & Less-successful & Total \\
\hline Balanced & No & 21 & 27 & 48 \\
& Yes & 9 & 3 & 12 \\
Structured & No & 26 & 27 & 53 \\
& Yes & 4 & 3 & 7 \\
Memory & No & 25 & 23 & 48 \\
& Yes & 5 & 7 & 12 \\
Learning & No & 19 & 26 & 45 \\
& Yes & 11 & 4 & 15 \\
Explorative & No & 24 & 18 & 42 \\
& Yes & 6 & 12 & 18 \\
Logical & No & 15 & 23 & 38 \\
& Yes & 15 & 7 & 22 \\
Analytical & No & 12 & 22 & 34 \\
& Yes & 18 & 8 & 26 \\
Reflective & No & 18 & 27 & 45 \\
& Yes & 12 & 3 & 15 \\
Impulsive & No & 29 & 25 & 54 \\
& Yes & 1 & 5 & 6 \\
Random & No & 26 & 12 & 38 \\
& Yes & 4 & 18 & 22 \\
Flexibility & No & 16 & 24 & 40 \\
& Yes & 14 & 6 & 20 \\
\hline
\end{tabular}

\subsection{Cognitive Styles and Cognitive Flexibility in the Proficiency Groups}

The table below indicates whether the cognitive styles and flexibility are markedly different between successful and less successful learners.

Table 2. Chi-Square inferential statistics for the proficiency groups

\begin{tabular}{lllll}
\hline Cognitive Styles & Chi-Square Values & $\begin{array}{l}\text { Pearson Chi-Square } \\
\text { Sig. }\end{array}$ & $\begin{array}{l}\text { Fisher's Exact Test } \\
\text { Sig. }\end{array}$ & $\begin{array}{l}\text { Effect Size } \\
\text { Values }\end{array}$ \\
\hline Balanced & 3.75 & .05 & .10 & .25 \\
Structured & .16 & .68 & 1.00 & .05 \\
Memory & .41 & .51 & .74 & .08 \\
Learning & 4.35 & $.03 *$ & .07 & .26 \\
Explorative & 2.85 & .09 & .15 & .21 \\
Logical Reasoning & 4.59 & $.03^{*}$ & .06 & .27 \\
Analytical & 6.78 & $.00^{*}$ & $.01^{*}$ & .33 \\
Reflective & 7.20 & $.00^{*}$ & $.01^{*}$ & .34 \\
Impulsive & 2.96 & .08 & .19 & .22 \\
Random & 14.06 & $.00^{*}$ & $.00^{*}$ & .48 \\
Cognitive flexibility/modifiability & 4.80 & $.02^{*}$ & .05 & .28 \\
\hline
\end{tabular}

As the values in the table suggest, there are remarkable differences between successful and less successful groups regarding 'Learning', 'Logical Reasoning', 'Analytical', 'Reflective', and 'Random' styles. There is also a considerable difference between the groups concerning cognitive flexibility. According to the frequencies provided in Table 1, it is indicated that the first four significant styles are more frequent in the successful group and the last one is notably prevalent in the less successful group. As regards cognitive flexibility, successful EFL learners are significantly more modifiable in their stylistic preferences. Notwithstanding that we found these differences, we obtained slightly divergent results by a more precise test, called Fisher Exact, and we found that the learning and logical reasoning styles are susceptible to be non-significant in this regard. This issue is also evident in the cognitive flexibility Fisher value (.05). Finally in the last column of the table, we provided the effect size values, Based on Cohen (1988), so as to find the magnitude of the obtained results. The learning, logical reasoning, and cognitive flexibility have relatively small to moderate, and the analytical, reflective, and random styles show medium to larger magnitudes. Among all, the highest effect size value belongs to the random style which was prevalent in the less successful learners group (.48). 
In the following lines, the Chi-Square inferential statistics for the gender groups are presented. Note that it was not necessary to provide the descriptive statistics for the following table since we compared four groups for the gender variable, and to show the areas of differences we presented the post hoc results through tables 4 to 6 .

\subsection{Cognitive Styles, Females versus Males in Proficiency Groups}

Table 3. Chi-square inferential statistics for the gender groups

\begin{tabular}{lllll}
\hline Cognitive Styles & Chi-Square Values & $\begin{array}{l}\text { Pearson Chi-Square } \\
\text { Sig. }\end{array}$ & $\begin{array}{l}\text { Fisher's Exact Test } \\
\text { Sig. }\end{array}$ & $\begin{array}{l}\text { Effect Size } \\
\text { Values }\end{array}$ \\
\hline Balanced & 5.83 & .12 & .18 & .31 \\
Structured & .48 & .92 & 1.0 & .09 \\
Memory & 2.50 & .47 & .52 & .20 \\
Learning & 5.24 & .15 & .16 & .29 \\
Explorative & 5.39 & .14 & .12 & .30 \\
Logical Reasoning & 11.77 & $.00^{*}$ & $.01 *$ & .44 \\
Analytical & 6.78 & .07 & .06 & .33 \\
Reflective & 11.64 & $.00^{*}$ & $.00^{*}$ & .44 \\
Impulsive & 3.70 & .29 & $.00^{*}$ & .24 \\
Random & 16.93 & $.00^{*}$ & .06 & .53 \\
Cognitive flexibility/modifiability & 7.80 & .05 & & .36 \\
\hline
\end{tabular}

This table indicates that three of the cognitive styles were significantly different among gender groups, including: logical reasoning, reflective, and random. The related Fisher Exact values also revealed that the relationships are significant and the values of effect size are large enough as well. To find the location of the differences, we conducted three post hoc tests by calculating the Z-scores, Chi-Square values, and $\mathrm{P}$ values which were done according to the procedure recommended by Beasley \& Schumacker (1995).

Table 4. Chi-square residuals post-hoc testing for the logical reasoning style

\begin{tabular}{llll}
\hline Groups & Z scores & Chi-Squares Values & P-Values \\
\hline LSM & -.92 & .85 & .84 \\
LSF & -1.54 & 2.37 & .50 \\
SM & -.92 & .85 & .84 \\
SF & 3.40 & 11.56 & $.01^{*}$ \\
\hline
\end{tabular}

The compared groups in Table 4 are LSM (Less Successful Males), LSF (Less Successful Females), SM (Successful Males), and SF (Successful Females). As this table illustrates, the SF group is significantly different from other groups, which indicates that successful females were more inclined to logical reasoning style.

Table 5. Chi-square residuals post-hoc testing for the reflective style

\begin{tabular}{llll}
\hline Groups & Z scores & Chi-Square Values & P-Values \\
\hline LSM & -.51 & .26 & .97 \\
LSF & -2.58 & 6.66 & .08 \\
SM & .20 & .04 & 1.00 \\
SF & 2.93 & 8.58 & $.04 *$ \\
\hline
\end{tabular}

According to this table, there is a significant difference between SF and other groups which shows that females in the successful group solved the CPP's problems in a more reflective manner. However, this difference is not as much as the difference found regarding logical reasoning style. 
Table 6. Chi-square residuals post-hoc testing for the random style

\begin{tabular}{llll}
\hline Groups & Z scores & Chi-Squares Values & P-Values \\
\hline LSM & .93 & .86 & .83 \\
LSF & 3.40 & 11.56 & $.01^{*}$ \\
SM & -1.55 & 2.40 & .49 \\
SF & -2.78 & 7.73 & .05 \\
\hline
\end{tabular}

Table 6 demonstrates that it was the LSF group that tended to do the cognitive test in a random and disorganized way (.01). Although the SF group showed the $\mathrm{P}$ values of .05 , its $\mathrm{Z}$ score is negative which means that the SF were almost far from being inclined to random style.

\subsection{The Correlational Analyses for the CPP Experience Evaluation}

As was mentioned earlier, another purpose of this study was to examine the EFL learners' experience evaluation and its relationship with FL achievement and gender. The table below illustrates possible relationships between EFL success and evaluation responses. This was conducted, using Gamma Correlation coefficients.

Table 7. Gamma correlation coefficients for the proficiency groups

\begin{tabular}{lll}
\hline Evaluation Questions & Correlation Coefficient & Sig. \\
\hline 1. How well did you understand the test? & .36 & .11 \\
2. How difficult did you find the test? & -.20 & .47 \\
3. How well do you think you did? & .43 & .06 \\
4. Were you anxious or afraid? & .21 & .33 \\
5. How well could you concentrate? & -.00 & .97 \\
6. How much did you enjoy the test? & .15 & .46 \\
\hline
\end{tabular}

As Table 7 shows, no statistically significant relationship was found between FL success and experience evaluation. However, the relationship between EFL success and the question number 3 is not too far from the significance level (.06) and the relation is also positive. In addition, the direction of the relationships are negative regarding the assessment of the difficulty of the test (question 2) and the participants' concentration in the proficiency groups (question 5). To put it simply, less successful learners were slightly more likely, though not significant, to have less concentration and think that the CPP was difficult. To gain more information about the evaluation items, see Appendix C.

Table 8. Gamma correlation coefficients for the gender groups

\begin{tabular}{lll}
\hline Evaluation Questions & Correlation Coefficient & Sig. \\
\hline 1. How well did you understand the test? & -.00 & .96 \\
2. How difficult did you find the test? & -.25 & .25 \\
3. How well do you think you did? & -.13 & .46 \\
4. Were you anxious or afraid? & -.04 & .81 \\
5. How well could you concentrate? & .14 & .39 \\
6. How much did you enjoy the test? & -.15 & .32 \\
\hline
\end{tabular}

This table implies that there is no noticeable relationship between gender and evaluations on the test experience. The only positive correlation value belongs to the question number 5 which means that males had higher concentration, however, this was not a significant relationship.

\section{Discussion}

Several types of cognitive styles, plus the cognitive flexibility, were contrasted in the proficiency groups to answer the research questions 1 and 2. As was demonstrated, successful EFL learners had analytical and reflective styles among their dominant cognitive styles. These results were also obtained by Biedron \& Szczepaniak (2009). Besides, successful learners were cognitively flexible which is in harmony with many of the earlier research results, such as Chapelle \& Roberts (1986), Ehrman \& Oxford (1985), and Biedroń \& Szczepaniak (2009). As regards logical reasoning, the active role of its nearest examined thinking type, called critical thinking, has been acknowledged in the SLA (Second Language Acquisition) studies as an essential higher-order thinking skill for language learners (Chamot, 1995; Davidson, 1994; Liaw, 2007; Shen \& 
Yodkhumlue, 2012).Good language learners also showed a significant tendency toward the "Learning" style. From the definition of this style (Appendix B), it can be discerned that this is a tendency to grasp new ideas. This was also highlighted in many studies regarding good language learners (Hedge, 2000; Lightbown \& Spada, 1997; Rubin \& Thompson, 1994). The additive point here is that learning is seen as a cognitive style which is partially stable, and thus it is not merely a willingness to learn new things in the target language. In fact, it is a strong cognitive tendency toward acquiring new ways of thinking. Among the significant styles, the effect size of the random style was the largest one and others were around .3 which is medium.

As it happens, a language learner may not have one particular cognitive style and the CPP does not put respondents into one category of style unless they are too rigid in one particular style. Therefore, it is not appropriate to consider good or poor language learners as having one thinking style. In fact, they have a battery of characteristics that lead them to achieve higher or lower proficiency in a new language. This idea was advocated by Ehrman \& Oxford (1990), in that "In reality, each language learner is a complex composite of all eight of these learning-style approaches" (p. 311).

Good FL learners may, in fact, be cognitively more efficient who do not stick to a particular way of processing information and can handle and adjust various stylistic preferences in a reasonable way. On the other hand, we found that less successful EFL learners acted randomly and unsystematically while completing the cognitive test. Considering this, the idea of Ehrman \& Leaver (2003), does not support the result of this study about the random style. This may be due to their definition of random style which is different from that of the CPP in that the E\&L focused on the idiosyncratic nature of the random style, rather than the disorganized problem-solving behaviors ascribed to this style in the CPP's style description (Appendix B).

The results obtained by the present study may partially explain the existing controversies in impulsive/reflective studies since it suggests that there may be other stylistic preferences, other than or in addition to impulsivity, which intervene insufficient language learning and this may be an unplanned and undisciplined thinking approach. The impulsivity measures, in particular, was the main concern of a recent investigation by Glicksohn, Hadad, \& Ben-Yaacov (2016), in which they concluded that an incorporation of different measurement approaches, such as self-report and performance analyses will plausibly lead to a more valid and comprehensive result, because the respondents' impulsivity is less consistent in different tests, probably due to the test occasions. Inevitably, future investigations may shed more light on the impulsive/reflective styles to see whether they are stable cognitive preferences or are merely dependent upon the participants' mood, the test, and its environment. Although Jamieson (1992) and Morovat (2014) also found that there is no relationship between reflectivity/impulsivity dimensions and IELTS band scores, we further found other cognitive characteristics in poor EFL learners' group, a disorganized problem solving orientation (i.e., random style), together with a lower cognitive flexibility. Therefore, the impulsive style per se may not be the primary or the only influential cognitive style to be considered in this regard, suggesting that we should consider other unexamined cognitive preferences along with previously recognized styles. That is why we recommend innovative multidimensional measurement tools so as to find more salient cognitive variables that could account for some of the unresolved problems in this research area.

Turning to the gender differences, we found that females were generally more inclined to be reflective language learners. This was supported by some studies (Harrison \& Nadelman, 1972; Messer, 1976). Furthermore, females in the successful group were considerably disposed toward logical reasoning, which "is aided by the conscious, reflective processing system" (DeWall, Baumeister, \& Masicampo, 2008, p. 628). With respect to the random style, LSF showed the highest tendency. Finally, as an answer to question 4, no notable difference was found between males and females in terms of their cognitive flexibility. We acknowledge that the explanation of the results concerning the gender groups is a great challenge in its own right. Firstly, because the instrument used in this study has never been employed in any EFL study. Secondly, the history of results about males/females language learners' differences are considerably inconsistent and thus make it improbable to draw a generalizable conclusion. The replications of this study on a large-scale research, using the CPP or other innovative instruments, would unveil whether men and women are significantly different in this domain.

A crucial caveat to consider is that the outperformance of proficient learners may have been due to their bilingual benefit and not merely to their innate mental characteristics which existed before EFL success. For instance, Marian \& Shook (2012), indicated that earlier research affirmed the cognitive benefits of the bilingual brain, especially in attention and task-switching capabilities. Besides, Planchon \& Ellis (2012), found that bilinguals performed considerably better than monolinguals in language aptitude test. Albeit, they did not compare proficient bilinguals with less proficient ones. Accordingly, Sáfár \& Kormos (2008), declared that language learning experience can affect language aptitude. Recently, another cognitive benefit of bilinguals was put 
forward by Poepsel \& Weiss (2016), determining that bilinguals were better at handling variability in statistical learning (Note 3), which is "a fundamental component of language acquisition" (p. 9). Nevertheless, this has currently become a celebrated debate in bilingual studies and the new arguments have questioned the exaggerated benefits of multilingualism. As an appreciable example from a comprehensible review, de Bruin, Treccani, \& Della Sala (2014), concluded that the real image of the bilingualism research is distorted due to the bias against publishing negative or insignificant results related to the bilingual benefit studies. Consequently, further study is strongly recommended in order to clarify this issue in a cooperative and multidisciplinary framework.

As a response to the questions $(5 \& 6)$ concerning the experience evaluation, we found no significant relationship in this regard. It means that none of the groups were considerably superior or inferior to others, particularly in understanding and concentration, at least based on their own perception. This self-perception and its importance have been emphasized in many studies (Chu, Guo, \& Leighton, 2013; Falchikov \& Boud, 1989; Schunk, 2005). Although we did not find any significant relationship in this regard, the directions of some of the relationships may be interesting to note. As an exemplification, highly proficient learners think they did well on the test, though not significant (.066). Regarding gender groups, no notable relationship was found. It might be due to either small sample size or the gender factor which may not be influential in this regard. Only further studies could clarify and explain this.

\subsection{Implications}

The pedagogical implications can be sought for both teachers and learners. As a clarification, FL classrooms are influenced by the teachers' cognitive styles since their tendencies will help much to reflect and explain the way they teach (Riding, 2002). Thereupon, it gives both educators and students more self-awareness to track their own teaching and learning processes. According to Cohen \& Dörnyei (2002), the leading implication of this issue lies in an efficient classroom where teachers adapt the tasks in the classroom for the purpose of maximization of the capabilities of learners with all their cognitive differences. The adaptation idea was also supported by Evans (2004), plus the point that students with more rigid styles need more help from their teachers and thus teachers' cognitive style should be taken into account as well. Moreover, Shipman (1989), recommended focusing on a more careful task analysis of learners and concluded that "It is not until we understand how a learner responds "successfully" that we can help those who are less successful to change their behavior" (p. 12). Additionally, language learners will become more flexible when they learn to take notice of both structure and meaning from the beginning stages (Reiss, 1981). In the same vein, Hwu, Pan, \& Sun (2014) contended that apart from explicit teaching, aptitude-treatment may lead second language learners to success.

\subsection{Limitations}

Turning to the main limitations of this study, we must acknowledge some shortages. First and foremost, the sample was not large enough to generalize the results to a broad population. This issue was caused by the time required to do the test. It took each participant at least one hour to finish the test, and many IELTS learners were not free to participate in the study. Secondly, using such a novel cognitive test in the domain of EFL success led us to be more cautious and conservative in interpreting the obtained results. Finally, there are many other variables which could interfere the results, such as the impact of bilingualism (Poepsel \& Weiss, 2016) and the participants' university majors (Lee \& Oxford, 2008; Liu, 2015). It is inevitable that even the influence of the first language abilities was mentioned in this regard (Castilla, Adelaida, \& Perez-Leroux, 2009).

\section{Conclusion}

From the outcomes of our investigation, it is possible to conclude that style rigidity, even in highly valued styles (i.e., analytic and reflective) may not lead to FL success, owing to the fact that language learning is a multifaceted skill acquisition. To put it differently, learning a new language is not equal to knowing grammars or vocabularies with rules and details, nor is it simply communicating and extracting overall meaning. In fact, FL learning is a combination of all these skills which tap into different cognitive capabilities and abilities simultaneously. Consequently, having enough cognitive flexibility conspicuously assists learners in the FL acquisition process, especially in the troublesome phases. The importance of this cognitive trait was also highlighted by Demetriou \& Raftopoulos (2005), in their definition of a real intelligent person. We suggest that those cognitive styles with higher values may not always be helpful in FL success unless they are adjustable on various occasions and tasks. Last but not least, the impact of attitudinal factors like experience and self-evaluation should also be taken into consideration since they may play a role in the way learners do a test and the way they perceive their performance.

Some recommendations seem to be substantial and critical. First and foremost, it is effectual to replicate the 
present study with larger samples in different contexts (i.e., in SL environments), along with the inclusion of more variables in the studies so as to reach more precise results. The replication seems crucial since the test used in the present research was unique, both in its theoretical foundation and its application, and thus this may be a starting point for the long way of a new trend in cognitive studies related to the EFL field of study. The possible impact of the gender factor should be considered in future studies as well to see if there are some gender-related patterns, particularly in language learning achievements. Furthermore, it seems beneficial to investigate the impacts of bilingualism and multilingualism for a better understanding of the relationships existing among innate cognitive traits, bilingualism effects, and high/low FL achievement.

The final suggestion is for both the test providers and researchers. They should collaborate more, especially in educational fields since many innovative tests like the CPP are relatively unknown among authors due to both policies of the companies and the research communities' disconnection from the psychometricians. Thereupon, it seems beneficial to look for innovative research tools and to establish cooperation with test providers. This collaboration may lead to a unified research society in cognition studies and thus can pave the way for new questions to be asked and may also create many chances to work on unaddressed issues of the earlier studies by the use of reliable and valid research tools. This federation will also assist psychometricians to improve and redound to their tests' validity and reliability. In sum, the take-home message is to encourage EFL/ESL researchers to use more naturalistic and process-based psychometric tools instead of unidimensional and outcome-based ones and try to incorporate new insights into the EFL/ESL studies in general and to throw some new light upon internal facilitators of the FL/SL success in particular.

\section{Acknowledgements}

We are sincerely thankful for all the support from the Cognadev (C) team, especially Maretha Prinsloo, Lorette Theron, and Paul Barrett, from holding training sessions to providing useful recourses, and pieces of advice.

Many thanks also go to the Afarinesh IELTS-House team in Tehran for allowing us to find targeted EFL learners, and also for permitting the administration of the CPP at the center.

\section{References}

Arnup, J. L., Murrihy, C., \& Roodenburg, J. (2013). Cognitive style and gender differences in children's mathematics achievement. Educational Studies, 39(3). http://dx.doi.org/10.1080/03055698.2013.767184

Bakhoda, I., \& Shabani, K. (2016). Response latency as a tool to study L2 Learners' ZPD, ZAD and ongoing information processing. Asian-Pacific Journal of Second and Foreign Language Education, 1(2), 1-16. https://doi.org/10.1186/s40862-016-0009-4

Barrett, P. (2015). Retest Reliability of the Cognitive Process Profile (CPP) (Report No. 5). South Africa: Cognadev Company.

Beasley, T. M., \& Schumacker, R. E. (1995). Multiple regression approach to analyzing contingency tables: Post hoc and planned comparison procedures. The Journal of Experimental Education, 64(1), 79-93. https://doi.org/10.1080/00220973.1995.9943797

Benson, P., \& Lor, W. (1999). Conceptions of language and language learning. System, 27(4), 459-472. https://doi.org/10.1016/s0346-251x(99)00045-7

Biedroń, A., \& Szczepaniak, A. (2009). The cognitive profile of a talented foreign language learner. A case study. Psychology of Language and Communication, 13(1), 53-71. https://doi.org/10.2478/v10057-009-0004-7

British Council. (n. d.). IELTS Guide for teachers. Retrieved from https://www.britishcouncil.it/sites/default/files/ielts_guide_for_teachers_italy.pdf

Brophy, J. (2004). Motivating students to learn. USA: Lawrence Erlbaum Associates.

Castilla, A. P., Adelaida, R., \& Perez-Leroux, A., T. (2009). Individual differences and language interdependence: a study of sequential bilingual development in Spanish-English preschool children. International Journal of Bilingual Education and Bilingualism, 12(5), 565-580. https://doi.org/10.1080/13670050802357795

Chamot, A. (1995). Creating a community of thinkers in the ESL/EFL classroom. TESOL Matters, 5(5), 1-16.

Chapelle, C., \& Roberts, C. (1986) Ambiguity tolerance and field independence as predictors of proficiency in English a a second language. Language Learning, 36(1), 27-45. https://doi.org/10.1111/j.1467-1770.1986.tb00367.x

Chu, M. W., Guo, Q., \& Leighton, J. P. (2013). Students' interpersonal trust and attitudes towards standardised tests: Exploring affective variables related to student assessment. Assessment in Education: Principles, 
Policy \& Practice, 21(2), 167-192. http://dx.doi.org/10.1080/0969594X.2013.844094

Cognadev. (2015). Cognitive Process Profile Standard Report for Research of Avarzamani (CPP03352). Johannesburg, South Africa: Cognadev

Cohen, A. D., \& Dörnyei. Z. (2002) Focus on the language learner: motivation, styles and strategies. In N. Schmitt (Ed.), An Introduction to Applied Linguistics. London: Edward Arnold.

Cohen, J. (1988). Statistical power analysis for the behavioral sciences (2nd ed.). Mahwah, NJ: Lawrence Erlbaum.

Davidson, B. (1994). Critical thinking: A perspective and prescriptions for language teachers. The Language Teacher, 18(4), 20-26.

Davies, J. (2009). A detailed analysis of the wholist-analytic style ratio: a methodology for developing a reliable and valid measure of style. Unpublished Ph.D. thesis, University of Glamorgan.

Davis, S. N. (1992). Sex Differences in Cognitive Abilities. Psychology of Women Quarterly, 16(4), 541-542. https://doi.org/10.1177/036168439201600403

De Bruin, A., Treccani, B., \& Della Sala, S. (2014). Cognitive advantage in bilingualism an example of publication bias? Psychological Science, 26(1), 99-107. https://doi.org/10.1177/0956797614557866

Demetriou, A., \& Raftopoulos, A. (2005). Cognitive Developmental Change: Theories, Models and Measurement. Cambridge: Cambridge University Press. https://doi.org/10.1017/cbo9780511489938

DeWall, C. N., Baumeister, R. F., \& Masicampo, E. J. (2008). Evidence that logical reasoning depends on conscious processing. Consciousness and Cognition, 17(3), 628-645. https://doi.org/10.1016/j.concog.2007.12.004

Ehrman, M. E. (1994). The Type Differentiation Indicator and language learning success. Journal of Psychological Type, 30, 10-29.

Ehrman, M. E., \& Leaver, B. L. (2003). Cognitive styles in the service of language learning. System, 31(3), 393-415. https://doi.org/10.1016/s0346-251x(03)00050-2

Ehrman, M. E., \& Oxford, R. L. (1995). Cognition Plus: Correlates of language learning success. The Modern Language Journal, 79(1), 67-89. https://doi.org/10.2307/329394

Ehrman, M., \& Oxford, R. (1990). Adult language learning styles and strategies in an intensive training setting. The Modern Language Journal, 74(3), 311-327. https://doi.org/10.2307/327627

Eska, B., \& Black, K. N. (1971). Conceptual tempo in young grade-school children. Child Development, 42, 505-516. https://doi.org/10.1111/j.1467-8624.1971.tb03655.x

Evans, C. (2004). Exploring the Relationship between Cognitive Style and Teaching Style. Educational Psychology, 24(4), 509-530. https://doi.org/10.1080/0144341042000228870

Evans, C., Cools, E., \& Zarina, M. C. (2010). Learning in higher education-how cognitive and learning styles matter. Teaching in Higher Education, 15(4), 467-478. https://doi.org/10.1080/13562517.2010.493353

Eysenck, M. W., \& Keane, M. T. (2015). Cognitive psychology: A student's handbook (7th ed.). Taylor \& Francis.

Falchikov, N., \& Boud, D. (1989). Student self-assessment in higher education: A metaanalysis. Review of Educational Research, 59(4), 395-430.

Frisby, B. N., Mansson, D. H., \& Kaufmann, R. (2014). The cognitive learning measure: A three-study examination of validity. Communication Methods and Measures, 8(3), 163-176. http://dx.doi.org/10.1080/19312458.2014.903389

Glicksohn, J., Hadad, Y., \& Ben-Yaacov, T. (2016). "Now you see me, now you don't": The assessment of impulsivity. Cogent Psychology, 3, 1-14. https://doi.org/10.1080/23311908.2016.1242682

Goel, V. (2010). Neural basis of thinking: Laboratory problems versus real-world problems. Wiley Interdisciplinary Reviews-Cognitive Science, 1(4), 613-621. https://doi.org/10.1002/wcs.71

Halpern, H. G. (1984). An investigation of reading and conceptual tempo measures. Reading World, 24(1), 90-96. https://doi.org/10.1080/19388078409557807

Harrison, A., \& Nadelman, C. (1972). Conceptual Tempo and Inhibition of Movement in Black Preschool Children. Child Development, 43(2), 657-668. https://doi.org/10.2307/1127564 
Hedge, T. (2000). Oxford Handbooks for Language Teachers. Oxford, UK: Oxford University Press.

Hwu, F., Pan, W., \& Sun, S. (2014). Aptitude-treatment interaction effects on explicit rule learning: A latent growth curve analysis. Language Teaching Research, 18(3), 294-319. https://doi.org/10.1177/1362168813510381

Jamieson, J. (1992). The cognitive style of reflection/impulsivity and field independence/dependence and ESL success. Modern Language Journal, 76(4), 491-501. https://doi.org/10.1111/j.1540-4781.1992.tb05398.x

Kagan, J. (1966). Reflection-impulsivity: The generality and dynamics of conceptual tempo. Journal of Abnormal Psychology, 71(1), 17-24. https://doi.org/10.1037/h0022886

Kaylani, C. (1996). The influence of gender and motivation on EFL learning strategy use in Jordan. In R. L. Oxford (Ed.), Language Learning Strategies Around the World: Cross-cultural Perspectives (pp. 75-88). Honolulu: Second Language Teaching and Curriculum.

Keller, J., \& Ripoll, H. (2001). Reflective-impulsive style and conceptual tempo in a gross motor task. Perceptual \& Motor Skills, 92(3), 739-749. https://doi.org/10.2466/pms.2001.92.3.739

Kozhevnikov, M. (2007). Cognitive styles in the context of modern psychology: toward an integrated framework of cognitive style. Psychological Bulletin, 133(3), 464-481. https://doi.org/10.1037/0033-2909.133.3.464

Kozhevnikov, M., Evans, C., \& Kosslyn, S. M. (2014). Cognitive Style as Environmentally Sensitive Individual Differences in Cognition: A Modern Synthesis and Applications in Education, Business, and Management. Psychological Science in the Public Interest, 15(1), 3-33. https://doi.org/10.1177/1529100614525555

Lee, K. R., \& Oxford, R. L. (2008). Understanding EFL learners' strategy use and strategy awareness. The Asian EFL Journal, 10(1), 7-32.

Liaw, M. (2007). Content-Based Reading and Writing for Critical Thinking Skills in an EFL Context. English Teaching \& Learning, 31(2), 45-87.

Lightbown, P. M., \& Spada, N. (1997). Learning English as a Second Language in a Special School in Quebec. Canadian Modern Language Review, 53(2), 315-355.

Littlemore, J. (2001). Metaphoric Competence: A language learning strength of students with a holistic cognitive style? TESOL Quarterly, 35(3), 459-491. https://doi.org/10.2307/3588031

Liu, H. J. (2015). Use of Learning Strategies by EFL Learners: A Study of How It Relates to Language Proficiency and Learner Autonomy. International Journal of English Linguistics, 5(2), 21-35. https://doi.org/10.5539/ijel.v5n2p21

Marian, V., \& Shook, A. (2012). The Cognitive Benefits of Being Bilingual, Cerebrum. Retrieved from http://dana.org/Cerebrum/2012/The_Cognitive_Benefits_of_Being_Bilingual

Marimuthu, R., Chone, L. S., Heng, L. T., Nah, E. A., \& Fen, O. S. (2013). Comparing the Online Learning Strategies of Male and Female Diploma Students of an English Language Course. Procedia-Social and Behavioral Sciences, 90, 626-633. https://doi.org/10.1016/j.sbspro.2013.07.134

McLeod, N. (2007). Cree narrative memory: From treaties to contemporary times. Saskatoon, Saskatchewan: Purich Publishing Limited.

Messer, S. B. (1976). Reflection-Impulsivity: A review. Psychological Bulletin, 83(6), 1026-1052. https://doi.org/10.1037//0033-2909.83.6.1026

Michonska-Stadnik, A. (2013). The Relationship between Impulsive/Reflective Cognitive Style and Success in Grammar Acquisition in English as a Foreign Language. In K. Drozdział-Szelest \& M. Pawlak (Eds.), Psycholinguistic and Sociolinguistic Perspectives on Second Language Learning and Teaching: Studies in Honor of Waldemar Marton (pp. 137-149). Berlin: Springer.

Miller, A. (1987). Cognitive styles: An integrated model. Educational Psychology, 7(4), 251-268. https://doi.org/10.1080/0144341870070401

Morovat, E. (2014). Effects of Reflectivity/Impulsivity on IELTS Candidates' Band Scores in the Speaking Module of the Test. Procedia-Social and Behavioral Sciences, 98, 1232-1239. https://doi.org/10.1016/j.sbspro.2014.03.538

Murray, B. (2010). Students' language learning strategy use and achievement in the Korean as a foreign language classroom. Foreign Language Annals, 43(4), 624-634. https://doi.org/10.1111/j.1944-9720.2010.01105.x

Niaz, M. (1987). Mobility-fixity dimension in Witkin's theory of field dependence-independence and its 
implication for problems solving in science. Perceptual and Motor Skills, 65(3), 755-764. https://doi.org/10.2466/pms.1987.65.3.755

Norton, B., \& Toohey, K. (2001). Changing perspectives on good language learners. TESOL Quarterly, 35(2), 307-322. https://doi.org/10.2307/3587650

O’Leary, M. R., Calsyn, D. A., \& Fauria, T. (1980). The group embedded figures test: A measure of cognitive style or cognitive impairment. Journal of Personality Assessment, 44(5), 532-537. https://doi.org/10.1207/s15327752jpa4405_14

Oxford, R. L., Ehrman, M., \& Lavine, R. Z. (1991). Styles wars: teacher-student style conflicts in the language classroom. In S. S. Margnan (Ed.), Challenges in the 1990s for College Foreign Language Programs (pp. 1-25). Boston, MA: Heinle \& Heinle.

Oxford, R. L., Nyikos, M., \& Ehrman, M. E. (1988) Vive la différence? Reflections on sex differences in use of language learning strategies. Foreign Language Annals, 21(4), 321-329. https://doi.org/10.1111/j.1944-9720.1988.tb01076.x

Planchon, A., \& Ellis, E. (2012). A Diplomatic Advantage? the Effects of Bilingualism and Formal Language Training on Language Aptitude amongst Australian Diplomatic Officers. Language Awareness, 23(3), 203-219. https://doi.org/10.1080/09658416.2012.742907

Poepsel, T. J., \& Weiss, D. J. (2016). The influence of bilingualism on statistical word learning. Cognition, 152, 9-19. http://dx.doi.org/10.1016/j.cognition.2016.03.001

Price, L. (2004). Individual Differenced in Learning: Cognitive control, cognitive style, and learning style. Educational Psychology, 24(5), 681-698. https://doi.org/10.1080/0144341042000262971

Prinsloo, M. (1992). A theoretical model and empirical technique for the study of problem solving processes. Doctoral thesis, Rand Afrikaans University, Johannesburg, South Africa.

Prinsloo, M. (2013). The cognitive Process Profile (CPP): Theoretical foundation, methodology and implications. Johannesburg: Cognadev (Pty) Ltd.

Prinsloo, M. (2016). The Cognadev Assessments: Based on Science or Intuition? Retrieved from http://www.cognadev.com/cognadev-assessments-based-science-intuition/

Prinsloo, M., \& Barrett, P. (2013). Cognition: Theory, Measurement, Implications. Integral Leadership Review. Retrieved from http://integralleadershipreview.com/9270-cognition-theory-measurement-implications

Ramsay, R. M. G. (1980). Language-learning approach styles of adult multilinguals and successful language learners. Annals of the New York Academy of Sciences, 345(1), 73-96. https://doi.org/10.1111/j.1749-6632.1980.tb51118.x

Reiss, M. A. (1981). Helping the unsuccessful language learner. The Modern Language Journal, 65(2), 121-128. https://doi.org/10.1111/j.1540-4781.1981.tb00960.x

Riding, R. J. (2002). School learning and cognitive style. London, UK: David Fulton Publishers Ltd.

Riding, R. J., \& Rayner, S. G. (1998). Cognitive styles and learning strategies. London: David Fulton. https://doi.org/10.4324/9781315068015

Royce, J. R., \& Powell, A. (1981). An overview of a multifactor-system theory of personality and individual differences: I. The factor and system models and the hierarchical factor structure of individuality. Journal of Personality and Social Psychology, 41(4), 818-829. https://doi.org/10.1037/0022-3514.41.4.818

Rubin, J., \& Thompson, I. (1994) How to Be a More Successful Language Learner. Boston, MA: Heinle \& Heinle.

Sáfár, A., \& Kormos, J. (2008). Revisiting Problems with Foreign Language Aptitude. International Review of Applied Linguistics in Language Teaching (IRAL), 46(2), 113-136. https://doi.org/10.1515/iral.2008.005

Salmani-Nodoushan, M. A. (2007). Is field dependence or independence a predictor of EFL reading performance? TESL Canada Journal, 24(2), 82-108. https://doi.org/10.18806/tesl.v24i2.140

Saricaoglu, A., \& Arikan, A. (2009). A Study of Multiple Intelligences, Foreign Language Success and Some Selected Variables. Journal of Theory and Practice in Education, 5(2), 110-122.

Schunk, D. H. (2005). Commentary on self-regulation in school contexts. Learning \& Instruction, 15(2), 173-177. https://doi.org/10.1016/j.learninstruc.2005.04.013 
Severiens, S., Dam, G. T., \& Nijenhuis, E. (1998). Ways of knowing and patterns of reasoning: Women and men in adult secondary education. Gender and Education, 10(3), 327-342. https://doi.org/10.1080/09540259820934

Shen, P., \& Yodkhumlue, B. (2012). A Case Study of Teacher's Questioning and Students' Critical Thinking in College EFL Reading Classroom. International Journal of English Linguistics, 2(1), 199-206. https://doi.org/10.5539/ijel.v2n1p199

Shipman, S. L. (1989). Limitations of applying cognitive styles to early childhood education. Early Childhood Development and Care, 5(1), 3-12. https://doi.org/10.1080/0300443890510102

Shouksmith, G. (1972). Self-concepts associated with two measures of cognitive style. New Zealand Psychologist, 1(2), 40-44.

Skehan, P. (1998). A Cognitive Approach to Language Learning. Oxford: Oxford University Press.

Tiedemann, J. (1989). Measures of cognitive styles: A critical review. Educational Psychologist, 24(3), 261-275. https://doi.org/10.1207/s15326985ep2403_3

Wei, X. (2008). Implication of IL Fossilization in Second Language Acquisition. English Language Teaching, 1(1) 127-131. https://doi.org/10.5539/elt.v1n1p127

White, C. (2008). Beliefs and good language learners. In C. Griffiths (Ed.), Lessons from Good Language Learner. New York: Cambridge University Press.

Williams, C. (1975). A study of cognitive preferences. Journal of Experimental Education, 43(3), 61-77. https://doi.org/10.1080/00220973.1975.10806338

Xu, Q. (2009). Moving beyond the Intermediate EFL Learning Plateau. Asian Social Science, 5(2), 66-68. https://doi.org/10.5539/ass.v5n2p66

Zelinker, T., Bentier, P. M., \& Renan, A. (1977). Speed vs. accuracy as a measure of cognitive style: Internal consistency and factor analyses. Child Development, 48(1), 301-304. https://doi.org/10.2307/1128916

Zhang, L. F., Sternberg, R. J., \& Rayner, S. (2012). Intellectual styles: Challenges, milestones, and agenda. Handbook of intellectual styles: Preferences in cognition, learning, and thinking. New York: Springer Pub.

\section{Notes}

Note 1. According to Eysenck \& Keane (2015), functional fixedness is "The inflexible function(s) of an object in problem solving" (p. 514).

Note 2. The tendency to use a familiar problem-solving strategy that has proved successful in the past even when it is not appropriate" (Eysenck \& Keane, 2015, p. 515).

Note 3. Statistical learning refers to "the process of detecting structure by monitoring distributional information available in the sensory input" (Poepsel \& Weiss, 2016, p. 9). 


\section{Appendix A}

\section{A Blurred Image of One of the CPP's Levels as a Sample}

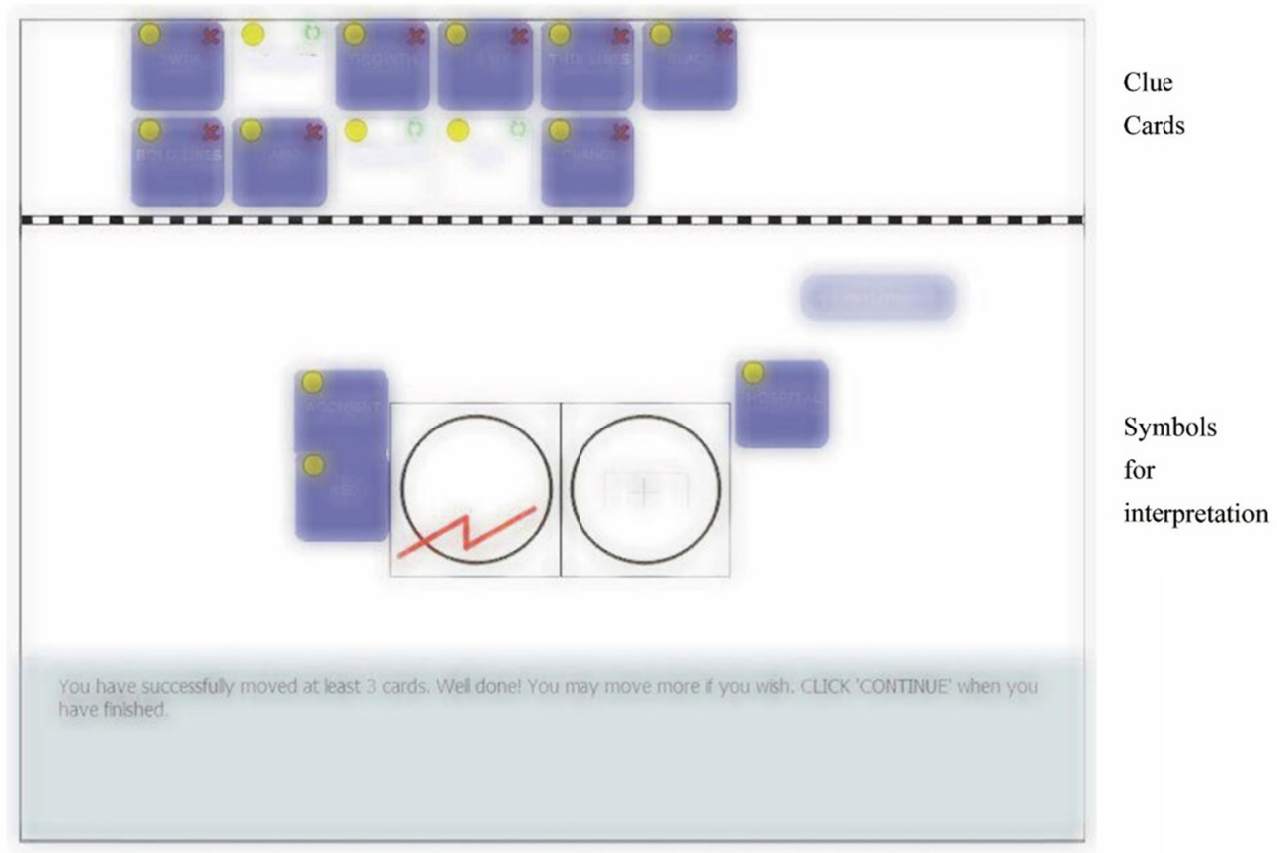

Note. *Adapted from the Cognadev (C), 2015.

\section{Appendix B}

\section{The CPP Cognitive Styles Descriptor}

\begin{tabular}{ll}
\hline Cognitive Styles & Definitions \\
\hline Balanced & The tendency to be flexible, use a variety of analytical and holistic approaches combined with a strong \\
learning orientation & The tendency to see the big picture whilst being aware of the relevant subcomponents and their \\
interconnections & \\
Holistic & The tendency for subconscious processing followed by quick grasp \\
Quick Insight & The tendency to tune into an insight and sense possibilities in vague situations \\
Intuitive & The tendency to apply rule-based arguments in a rigorous and intentional manner to generate convergent \\
Logical & and/or divergent solutions \\
& The tendency to synthesize and blend discrepant aspects to understand and formulate coherent and \\
Integrative & meaningful structures \\
Memory & The tendency to rely on already acquired knowledge and skill / past information to guide own approach and \\
& conclusions \\
The tendency to seek stimulation and acquire skill and understanding for the purpose of adaptation, growth, \\
mastery (The tendency to be adaptable, flexible and able to acquire new ways of thinking) \\
Analytical & The tendency to apply rules, work systematically, break the whole into subcomponents and identify \\
& interrelationships between components \\
The tendency to impose order on / contain an unstructured situation \\
Metaphoric & The tendency to represent the situation through symbols, metaphors, and abstractions \\
Explorative & The tendency to investigate situations in-depth and gather information \\
Reflective & The tendency to carefully consider situations and check facts and conclusions \\
Random & The tendency for an unplanned and random approach to unfamiliar environments (Working quickly but \\
Impulsive & likely to be inaccurate) \\
The tendency to act impulsively or emotionally without applying a rigorous approach
\end{tabular}

Note. *Adapted from the Cognadev (C), 2015. 


\section{Appendix C}

\section{The CPP Evaluation Questionnaire}

\begin{tabular}{llll}
\hline 1. How well did you understand the test? & Not at all & Not too well & Quite well \\
2. How difficult did you find the test? & Very hard & Fairly hard & Quite easy well \\
3. How well do you think you did? & Very badly & Fairly badly & Quite well Very easy \\
4. Were you anxious or afraid? & Very anxious & Quite anxious & Fairly relaxed \\
5. How well could you concentrate? & Not well at all & Not very well & Fairly well \\
6. How much did you enjoy the test? & Not at all & A bit & Quite a lot
\end{tabular}

Note. *Adapted from the Cognadev (C), 2015.

\section{Appendix D}

\section{IELTS Band Descriptors}

\begin{tabular}{|c|c|c|}
\hline $\begin{array}{l}\text { Band } \\
\text { Score }\end{array}$ & Skill Level & Description \\
\hline 9 & Expert User & Has fully operational command of the language: appropriate, accurate and fluent with complete understanding. \\
\hline 8 & $\begin{array}{l}\text { Very good } \\
\text { user }\end{array}$ & $\begin{array}{l}\text { Has fully operational command of the language with only occasional unsystematic inaccuracies and } \\
\text { inappropriate words. Misunderstandings may occur in unfamiliar situations. Handles complex detailed } \\
\text { argumentation well. }\end{array}$ \\
\hline 7 & Good user & $\begin{array}{l}\text { Has operational command of the language, though with occasional inaccuracies, inappropriate words and } \\
\text { misunderstandings in some situations. Generally handles complex language well and understands detailed } \\
\text { reasoning. }\end{array}$ \\
\hline 6 & $\begin{array}{l}\text { Competent } \\
\text { user }\end{array}$ & $\begin{array}{l}\text { Has generally effective command of the language despite some inaccuracies, inappropriate words and } \\
\text { misunderstandings. Can use and understand fairly complex language particularly in familiar situations. }\end{array}$ \\
\hline 5 & Modest user & $\begin{array}{l}\text { Has partial command of the language, coping with overall meaning in most situations, though is likely to make } \\
\text { many mistakes. Should be able to handle basic communication in own field. }\end{array}$ \\
\hline 4 & Limited user & $\begin{array}{l}\text { Basic competence is limited to familiar situations. Has frequent problems in understanding and expression. Is } \\
\text { not able to use complex language. }\end{array}$ \\
\hline 3 & $\begin{array}{l}\text { Extremely } \\
\text { limited user }\end{array}$ & $\begin{array}{l}\text { Conveys and understands only general meaning in very familiar situations. Frequent breakdowns in } \\
\text { communication occur. }\end{array}$ \\
\hline 2 & $\begin{array}{l}\text { Intermittent } \\
\text { user }\end{array}$ & $\begin{array}{l}\text { No real communication is possible except for the most basic information using isolated words or short } \\
\text { formulae in familiar situations and to meet immediate needs. Has great difficulty understanding spoken and } \\
\text { written English. }\end{array}$ \\
\hline 1 & Non user & Essentially has no ability to use the language beyond possibly a few isolated words. \\
\hline $\mathbf{0}$ & $\begin{array}{l}\text { Did not } \\
\text { attempt } \\
\text { the test }\end{array}$ & No assessable information provided. \\
\hline
\end{tabular}

Note. *Adapted from IELTS Guide for teachers, n. d.

\section{Copyrights}

Copyright for this article is retained by the author(s), with first publication rights granted to the journal.

This is an open-access article distributed under the terms and conditions of the Creative Commons Attribution license (http://creativecommons.org/licenses/by/4.0/). 